\title{
Benign Prostatic Hyperplasia
}

National Cancer Institute

\section{Source}

National Cancer Institute. Benign Prostatic Hyperplasia. NCI Thesaurus. Code C2897.

A non-cancerous nodular enlargement of the prostate gland. It is characterized by the presence of epithelial cell nodules, and stromal nodules containing fibrous and smooth muscle elements. It is the most common urologic disorder in men, causing blockage of urine flow. 